\title{
Enterprise and Innovation
}

\section{Monetary Policy Transparency and Pass-Through of Retail Interest Rates}

\section{Ming-Hua Liu, Dimitri Margaritis and Alireza Tourani-Rad}

Research Paper Series

Faculty of Business ISSN Number 1176-1997 


\section{MONETARY POLICY TRANSPARENCY AND PASS-THROUGH OF RETAIL INTEREST RATES}

\section{Ming-Hua Liu, Dimitri Margaritis and Alireza Tourani-Rad}

Dimitri Margaritis

Faculty of Business Auckland University of

Technology

Private Bag 92006

Auckland 1020

New Zealand

Tel: +64-(0)9-917-9999 x5394

Fax: +64-(0)9-917-9876

e-mail: dimitri.margaritis@aut.ac.nz

Ming-Hua Liu *
Faculty of Business
Auckland University of
Technology
Private Bag 92006
Auckland 1020
New Zealand
Tel: +64-(0)9-917-9999 x5398
Fax: +64-(0)9-917-9876
e-mail: ming.liu@aut.ac.nz
* Author for Correspondence

Alireza Tourani-Rad Faculty of Business Auckland University of Technology Private Bag 92006 Auckland 1020 New Zealand Tel: +64-(0)9-917-9999 x5336 Fax: +64-(0)9-917-9876 e-mail: alireza.touranirad@aut.ac.nz

The opinions and views expressed in this paper are those of the author(s) and not necessarily those of AUT of the General Editor or Review Panel of Enterprise and Innovation. 


\section{AUT AUTHORS}

\section{AsSOCIATE PROFESSOR MING-HUA LIU}

Dr Liu is currently an associate professor of finance with expertise in banking, investments and financial risk management. Dr Lui worked in the financial services industry for twelve years prior to joining AUT, and his research articles have appeared in the Journal of Banking and Finance, Pacific Basin Finance Journal, Advances in Pacific Basin Financial Markets, Advances in Pacific Business, Economics and Finance, and Law and Policy in International Business. He is an associate editor of African Finance Journal. Dr Liu's research has won best paper awards in major international finance conferences and also received the teacher of the year award.

\section{PROFESSOR DIMITRI MARGARITIS}

Dimitri Margaritis is Professor of International Finance in the Faculty of Business. He was previously Professor of Economics at the University of Waikato and has in the past held academic appointments at SUNY-Buffalo, Southern Illinois University, the University of Washington, and the University of British Columbia. He served as Advisor and Manager of Research at the Reserve Bank of New Zealand in the early 1990s and was subsequently appointed as the Bank's Senior Research Fellow while he returned to teach at Waikato Universiity. He was a member of the World Bank's project on Financial Reform and is currently the leader of the New Zealand Enterprise Efficiency and Productivity project funded by the Foundation for Research, Science and Technology. He has published extensively in the international refereed literature in monetary policy, international finance, health economics, economic growth and productivity.

\section{Professor AliREZA TOURANI-RAD}

Dr. Alireza Tourani-Rad is a Professor in Finance and head of the Finance Research Centre. His previous positions include Professor of Finance at the University of Waikato Management School and Associate Professor at Masstricht University in the Netherlands. Dr. Tourani-Rad specialises in the corporate and international finance areas. He completed his Ph.D. at the Free University of Brussels and his Masters' degree at the Catholic University of Leuven in Belgium. He was Executive Vice President of the European Financial Management Association and Secretary of the Limburg Institute of Financial Economics. He has held visiting positions at a number of leading European Universities and has published extensively in international journals. 


\title{
MonetaRy Policy TRANSPaRency and PASs-Through of Retall INTEREST RATES
}

\begin{abstract}
This paper examines the degree of pass-through and adjustment speed of retail interest rates in response to changes in benchmark wholesale rates in New Zealand during the period 1994 to 2004. We consider the effect of policy transparency and financial structure in the transmission mechanism. New Zealand is the first OECD country to adopt a formal inflation targeting regime with specific accountability and transparency provisions. Policy transparency was further enhanced by a shift from quantity (settlement cash) to price (interest rate) operating targets in 1999. We find complete long-term pass-through for some but not all retail rates. Our results also show that the introduction of the Official Cash Rate (OCR) increased the pass-through of floating and deposit rates but not fixed mortgage rates. Overall, our results confirm that monetary policy rate has more influence on short-term interest rates and that increased transparency has lowered instrument volatility and enhanced the efficacy of policy.
\end{abstract}

JEL classification: E43

Key Words: $\quad$ Monetary Policy, Transmission Mechanism, Interest Rates 


\section{INTRODUCTION}

Monetary policy is the primary tool of macroeconomic management in nearly all industrialized countries. When monetary policy needs to be tightened (loosened), the central bank or monetary authority will increase (decrease) the official interest rate, banks and other types of financial institutions will follow suit by raising (reducing) their deposit and lending rates. Faced with higher (lower) cost of funds, consumers and companies will adjust their consumption and expenditure accordingly, thus affecting output and inflation. The efficacy of monetary policy thus depends on how fast and to what extent financial institutions pass through changes in the official rate to their customers.

While there are numerous studies on monetary policy transmission, the retail interest rates pass-through process is relatively under-explored, at least until recently. Most of the studies on the transmission mechanism of monetary policy assume immediate and complete pass-through of changes in official rates to retail bank rates (for example, Bernanke and Gertler, 1995; Kashyap and Stein, 2000; Altunbas et al, 2002). Recent studies show that the pass-through may be incomplete and that the adjustment speed may be sluggish. The passthrough and adjustment speed also differ across financial institutions and across financial products, which implies that the speed of monetary transmission varies across different segments of the banking sector. Further, some studies also find that the adjustment speed is different depending on whether rates are above or below their long-term equilibrium level (Chong et al, 2005; Kleimeier and Sander, 2005).

In this study, we examine the degree of pass-through and adjustment speed of retail interest rates when benchmark interest rates change in New Zealand. Specifically, we analyze the following issues: Firstly, we consider the 
long-term pass-through of the official rate and interbank rate to various retail interest rates such as deposit and lending rates including the base lending rate and mortgage rates of different maturities. We employ the Phillips-Loretan (1991) methodology which eliminates asymptotic bias problems and allows for meaningful statistical inferences on the long-run coefficients. By incorporating the effect of dynamics in the data generation process (DGP), this method also accounts explicitly for the role of past policy surprises and future expected policy settings in the relationship between retail rates and policy instruments. Secondly, we examine the short-term pass-through and the adjustment speed of retail interest rates using an error correction model and also test whether the adjustment speed is symmetric or asymmetric. Finally, we investigate whether a change in monetary policy operating procedures and increased transparency of monetary policy as a result of the adoption of the Official Cash Rate (OCR) instrument in 1999 has had a different effect on the pass-through and adjustment speed of interest rates in New Zealand.

There are at least three reasons why a study of the New Zealand transmission mechanism is important. Firstly, New Zealand is the first country to adopt an explicit inflation targeting regime with specific accountability and transparency provisions. These arrangements became a prototype model for the policy frameworks adopted by other OECD countries and more recently a number of developing countries. Secondly, unlike most other countries, there was a major shift in the monetary control mechanism in New Zealand during this period away from quantity targets (settlement cash balances) and towards price based (OCR) settings. Although under either of these two regimes the transmission of monetary policy would operate primarily through interest rates, the question is whether and to what extent there will be a change in the degree and adjustment speed of pass-through from policy instruments to retail rates and by implication to the effectiveness of monetary control. We would expect that under a price regime the role of interest rates in the transmission mechanism will become much more transparent. Settlement cash balances, unlike interest rates 
(and exchange rates), do not normally have a stable relationship with nominal income or inflation and generally lead to considerably higher interest rate volatility compared to an interest rate target. Quantity targets do, however, offer certain operating advantages as they provide a better cushion against accommodating unintentionally inflationary increases as is often the case under an interest rate targeting regime. They also facilitate a rapid interest rate response which may be crucial during periods of high or renewed inflationary pressures (see Spencer, 1992).

The third reason relates to the observation that New Zealand is one of the most heavily indebted OECD countries and its household sector has negative savings rate. The banking sector, almost all foreign owned, relies more and more on overseas borrowing. It would be interesting to see the effectiveness of monetary policy when there are leakages in the system. According to official statistics by the Reserve Bank of New Zealand, as of March 2005, the private sector's foreign debt was NZ\$149 billion, or 101 percent of New Zealand's GDP, which is 8.8 times more than the government's overseas debt (NZ\$17 billion, or 12 percent of GDP). While the business sector has increased their savings due to higher profits, the household savings have been declining steadily. The New Zealand household sector has one of the lowest savings rates among the OECD countries. According to Statistics New Zealand, households in New Zealand on average do not save anything out of current income but, instead, "dis-save" about 12 percent of income per year. Residential mortgage debt accounts for 90 percent of the total household debt which in turn accounts for over 50 percent of the total loan portfolio of all New Zealand's financial institutions. ${ }^{i}$ As a result of the shortage of local savings, banks in New Zealand have been increasingly borrowing wholesale funds from overseas markets to meet the strong demand for mortgages, which may have some impact on the relationship between OCR and fixed-rate mortgages. 
Our findings show that the long-term pass-through of market interest rates to various retail rates differs across financial products. Some rates show complete pass-through while others do not. The short-term pass-through and adjustment speed also differ across products. We find no evidence that banks in New Zealand adjust their rates (both lending and deposit rates) up more slowly than they adjust them down. The introduction of OCR has increased the longterm pass-through of floating and fixed deposit rates, but had no impact on the other rates.

The remainder of the paper is organized as follows: Section 2 provides some institutional background on New Zealand monetary policy. Section 3 provides the conceptual framework and the literature review. Section 4 outlines our methodology. Section 5 discusses the data and results and the final section concludes the paper.

\section{Monetary Policy in NeW Zealand}

The Reserve Bank of New Zealand (RBNZ), New Zealand's central bank, is responsible for operating monetary policy independently to achieve price stability which is defined in the Policy Targets Agreement (PTA). The PTA is a specific and public contract negotiated between the Governor of the Reserve Bank and the Minister of Finance on behalf of the Government. It is an important component of the monetary policy framework as set out in the 1989 Reserve Bank Act. The current PTA, signed in September 2002, requires the Reserve Bank to keep inflation as measured by annual increase of CPI between 1 and 3 percent on average over the medium term.

In the 1990 and 1993 PTAs, price stability was defined to be 0 to 2 percent inflation over a one year period. The target band was widened to 0 to 3 percent in the December 1996 PTA. As inflation had actually been outside the target range 
on the upper side for nearly two years at that point and never below 1 percent, the new target band in essence did not represent a major shift in regime. However, pressing difficulties to keep inflation within the target band forced the Reserve Bank at the time to make a major shift in policy setting.

Previously, the Bank had set policy so as to avoid moving outside the target range a year ahead. It had made that judgment largely on the basis of the direct transmission effect from foreign prices through the exchange rate onto inflation (see Huang, Margaritis and Mayes, 2001). This in effect amounted to setting exchange rate bands as an intermediate target. Thereafter the Bank aimed to bring inflation info the middle of the target range 6 to 8 quarters ahead. This difference in both adopting a longer policy horizon and aiming towards the middle of the band represented a substantial change in the way policy was set. From July 1997 to March 1999, the RBNZ used a Monetary Conditions Index $(\mathrm{MCl})$ as a means of communicating its monetary policy requirements. Since March 1999, the RBNZ has changed its principal instrument of policy from managing the quantity of overnight cash to setting the interest rate for it (OCR). This rate is reviewed eight times a year.

Unlike most countries New Zealand did not set an interest rate as such prior to 1999. Instead the RBNZ influenced market conditions by specifying 90day bank bill rates that would be consistent with price stability - initially in combination with a range for the exchange rate and from late 1996 in terms of a Monetary Conditions Index that combined the two in a single measure. Although it could achieve any given market rate by use of quantitative controls in the overnight market - it set a 'cash target' for its daily market operations - the Bank did not normally have to use that weapon to achieve the market conditions it wanted. The combination of the threat that it could act and the statements explaining what was required were normally sufficient means of achieving its policy objectives. 
The Bank thus set policy through what have often been described as 'Open Mouth Operations' (Guthrie and Wright, 2000). Normally the quarterly Monetary Policy Statements were the vehicle used but in between times if there were shocks or the market moved too far the Governor or other senior members of the Bank would issue a brief statement saying what the Bank wanted. Unanticipated changes were infrequent and typically the Bank's settings will sanction market movements. By changing to an OCR setting the Bank adopted a more conventional Cash Rate instead of the quantitative target.

The OCR system is simpler and can be easily understood. iii It operates as follows: when an OCR is announced, the Reserve Bank is prepared to pay financial institutions an interest rate 0.25 percentage points below the OCR for their deposits with the Reserve Bank and is also prepared to lend overnight cash to banks against good security at an interest rate of 25 basis points above the OCR. More importantly, there is no limit on the amount of cash that it is willing to take in or let out at 25 basis points below and above the OCR, respectively. As the central bank acts as a market-maker in the short-term money market without any limits imposed on the amount traded, no commercial bank is likely to offer short-term loans at a rate significantly higher than the OCR. In a competitive financial system, other banks would undercut that by borrowing money from the Reserve Bank. Similarly, a financial institution is unlikely to lend short-term at much lower than the OCR since it can lend to the Reserve Bank at the OCR level, without any credit risk at all.

By lending or borrowing overnight money in unlimited volumes, the Reserve Bank is able to maintain the short-term interbank interest rate at the Bank's OCR level. By setting the OCR, the Reserve Bank can substantially affect other types of short-term interest rates, e.g., the 90-day bill rate, floating mortgages, etc. The OCR can also influence other retail interest rates administered by commercial banks and other types of financial institutions. As a result, changes in OCR will influence the overall level of economic activity in the 
country and hence inflation. However, this process takes time and the pace of adjustment speed varies across products and over time.

\section{Rigidities IN the INTERest RAte AdJustment PRocess}

The adjustment of retail interest rates by financial institutions to changes in monetary policy rate or benchmark money market interest rates is not spontaneous and the pass-through may be incomplete. In the industrial organization literature, a similar phenomenon in the goods market is known as price rigidity. The rigidity in the interest rate adjustment process is due to a number of factors that include fixed menu costs, high switching costs, imperfect competition and asymmetric information.

Under the menu costs hypothesis, banks are reluctant to change their interest rates if the changes of the benchmark interest rates are very small and/or temporary in nature (see Dutta et al., 1999). As there are adjustment costs involved in changing retail interest rates to bank customers, banks may respond slowly to temporary changes in monetary policy rate, but quickly to more permanent changes in policy rates.

Under the switching cost hypothesis, customers are unlikely to switch financial products and/or institutions in search of better funding or investment terms when there are high switching costs (see Heffernan, 1997). Customers need to spend time and effort to find out which bank offers the best deal and may find it too inconvenient and/or too costly to switch banks. For example, in the case of prepayment of loans and early withdrawal of time deposits by customers, some banks may charge a fee to make it costly for the customers to exercise those embedded options. The rigidity in interest rates may thus be attributed to the banks' exploitation of consumers' inertia in switching financial products and/or institutions. If banks can selectively price their products to exploit customers' inertia, then rates are expected to be rigid upwards for customer deposits, but 
downwards for loans. In other words, banks may adjust their deposit rate upwards more slowly and adjust their loan rate downwards more slowly. This will lead to asymmetry in the adjustment speed in interest rates.

Under the imperfect competition hypothesis, because of the collusive price arrangement among banks, rate adjustments in uncompetitive markets can be asymmetric, i.e., deposit rates are expected to be rigid upwards, while loan rates are expected to be rigid downwards (see Hannan and Berger, 1991, Neuman and Sharpe, 1992).

Finally, according to the asymmetric information hypothesis, banks face both adverse selection and moral hazard problems when they are required to raise loan rates in response to rising market interest rates (see Stiglitz and Weiss, 1981). The presence of agency costs makes banks more reluctant to increase loan rates significantly over a short period of time. Higher loan rates make loan payments more difficult for borrowers, leading to more problem loans and defaults. Unless their margins are under pressure and market rates are expected to remain high, banks are reluctant to raise loan rates. Instead, banks are more likely to ration the amount of credit extended to borrowers when there is an upward pressure on loan rates. As a result, loan rates are expected to be more rigid upwards under the asymmetric information model.

A combination of the above factors may play a different role in the retail interest rates' short-term and long-term adjustment process. Switching cost and menu costs, for example, are more likely to be the primary factors in influencing the short-term adjustment speed whereas imperfect competition and asymmetric information are more likely to be the primary factors in affecting the long-term pass-through (see Bondt, 2002).

Thus it becomes an empirical question as to whether the deposit rates and loan rates are more rigid upwards or downwards. Furthermore, it is also likely for 
the rigidity in retail interest rates to vary across different financial products. For example, such differences may be observed for loan rates versus deposits rates, floating mortgages versus fixed rate mortgages, short-term versus long-term rates, depending on the relative level of customers' inertia or the importance of switching costs. Customer inertia, for example, may be greater on saving deposit than on time deposits.

Hannan and Berger (1991) and Neuman and Sharpe (1992) were the first to study the stickiness of deposit rates. While assuming complete and immediate pass-through for retail lending rates, they examined the impact of market power in the deposit market on the stickiness of deposit rates in the United States. They found asymmetric adjustment in the deposit rate, i.e., banks adjust their deposit rates upwards more slowly than they adjust them downwards and they attributed it to banks' market power in the deposit market. Cottarelli and Kourelis (1994) were the first to study the pass-through to retail lending rates. Using an autoregressive distributed lag (ADL) model, they examined the response of lending rates in both developed and developing countries to changes in market interest rates. They found that interest rate pass-through differs across countries and that loan rate stickiness can be reduced by several factors: the existence of a market for short-term negotiable instrument, lower money market interest rate volatility, and relatively weak barrier to entry/competition.

Paisley (1994) and Heffernan (1997) examined the relationship between market rates and retail rates in the UK. Whilst Paisley (1994) did not find complete pass-thorough in mortgage rates for British building societies, Heffernan (1997) found complete pass-through in repayment mortgages but incomplete pass-through for current and savings accounts of British banks and building societies. Hofmann and Mizen (2004) studied 13 deposit and mortgage products of individual British financial institutions using a non-linear model and found complete pass-through for deposit rates but not for mortgage rates. 
Mojon (2000) examined the short-term pass-through to lending and deposit rates in five Euro-area countries, (Belgium, Germany, France, Netherlands and Spain), assuming there is full pass-through in the long term. He found that retail interest rates respond sluggishly to changes in money market rates; long-term rates respond more slowly than short-term rates, and there is an asymmetry in the degree of pass-through. Pass-through to lending rates is higher when market rates are increasing than when they are decreasing, but the opposite is true for deposit rates. Bondt (2002) examined the relationship between government bond yields and deposit and lending rates on a matchedmaturity basis for the Euro area as a whole. He found that pass-through is complete for most lending rates, but it is incomplete on impact for both deposit and lending rates. Kleimeier and Sander (2005) examined the pass-through in the euro-zone's retail banking markets and found that loan rates respond faster to changes in anticipated monetary impulses.

Chong et al (2005) examined the deposit rates of various maturities and lending rates of both commercial banks and finance companies in Singapore and found that financial institutions adjust their rates upwards more slowly than they adjust downwards. They also found that the adjustment speed differs across financial products and between banks and finance companies. They did not find complete pass-through of interest rates.

\section{Methodology}

In this paper, we examine both the long-run and short-run pass-through of monetary policy rates to various retail interest rates as well as the adjustment speed of the short-term dynamics to the long-term equilibrium relationship.

The long-term relationship between the retail interest rate and the benchmark market rate is expressed as:

$$
y_{t}=\alpha_{0}+\alpha_{1} x_{t}+\varepsilon_{t}
$$


where $y_{t}$ is the bank lending or deposit rate; $x_{t}$ represents the corresponding policy or money market rate; $\varepsilon_{t}$ is the error term; $\alpha_{0}$ and $\alpha_{1}$ are the long-run parameters. The interest rate series are expected to be integrated, $\mathrm{I}(1)$, variables and the error term is expected to be stationary. As discussed in Rousseas (1985), $\alpha_{0}$ measures the markup and $\alpha_{1}$ measures the degree of pass-through in the long term. The long-run pass-through is complete if $\alpha_{1}$ is statistically not different from one.

We estimate equation (1) using the Phillips-Loretan (1991) method. This method is well suited to the estimation of long-run relationship involving integrated variables where dynamics may play an important role in the DGP for $y_{t}$. It is modeled by the following triangular system of equations:

$$
\begin{aligned}
& y_{t}=\alpha+\beta^{\prime} x_{t}+u_{1 t} \\
& \Delta x_{t}=u_{2 t},
\end{aligned}
$$

where $u_{t}=\left[u_{1 t} u_{2 t}^{\prime}\right]^{\prime}$ is a stationary vector.

Equation (1a) can be estimated using single equation methods, and provided that the equation is appropriately augmented, the asymptotic properties of the estimator and its distribution can be readily determined. These properties hinge on the interrelationships that exist between $u_{1 t}$ and $u_{2 t}$, which are assumed to be stationary.

If the variance-covariance matrix of $u_{t}$ is block diagonal (so that the partitioned elements of the vector do not co-vary) and $u_{t}$ is also (i.i.d.) then equation (1a) can be estimated using least squares. The estimates will be normally distributed, at least asymptotically, and will be equivalent to maximum likelihood estimates of the parameters of the system. This result is important as it enables statistical inference using standard statistical tables to be used with integrated variables. 
If the variance covariance matrix of $u_{t}$ is block diagonal but the residuals are autocorrelated (but also block diagonal) the regression can be augmented with lagged error correction terms, counteracting the autocorrelation of $u_{1 t}$. This solution works because the regressors $-x_{t}-$ are super-exogenous. They are independent of the past and future history of $u_{1 t}$, i.e. they are orthogonal to $\left\{u_{1 t}\right\}_{t=-\infty}^{+\infty}$.

If $u_{1 t}$ and $u_{2 t}$ are correlated one can alleviate the problems that this causes by augmenting the regression with leads and lags of $\Delta x_{t}$. One can think of this as projecting $u_{1 t}$ against leads and lags of $u_{2 t}$ and then applying the Frisch -Waugh Lovell theorem. The error from the projection is uncorrelated with $u_{2 t}$, and the endogeneity or contemporaneity problem is thus dealt with. The inclusion of leads eliminates feedback from $u_{1 t}$ back to $u_{2 t}$ and it is important for valid conditioning. The basic problem is that, a priori, we do not know whether $u_{1 t}$ correlates with leads of $u_{2 t}$ or vice versa.

The inclusion of two-sided lag differences eliminates the endogeneity problem, while the autocorrelation problem may need to be remedied by including lags of the error correction term too. Phillips and Loretan then estimate the following equation using least squares:

$$
y_{t}=\alpha+\beta^{\prime} x_{t}+\sum_{k=1}^{K} d_{1 k}\left(y_{t-k}-\beta^{\prime} x_{t-k}\right)+\sum_{i=-l}^{L} d_{2 i} \Delta x_{t-i}+v_{1 t}
$$

Phillips and Loretan demonstrate that the parameter estimates from estimating this single equation are equivalent to maximum likelihood estimation of the system and hence are efficient. Furthermore, the parameters are asymptotically unbiased and normally distributed. In contrast, the OLS estimator of (1) while superconsistent is not asymptotically unbiased or normally distributed 
and its finite sample bias may be large and persistent. An added advantage of considering the specification given by $(1 \mathrm{c})$ is that it accounts explicitly for the role of past policy surprises and future expected policy settings in the relationship between retail rates and policy instruments.

Equation (1) is a long run model. As monetary policy rate changes, banks will not adjust their retail rates immediately. Short-term rates are expected to be adjusted more quickly than medium and long-term rates since the latter depend on future short-term rates as well as current short-term rates.

To examine the short-run dynamics of interest rate changes in response to changes in the policy or money market rates, we employ a structural errorcorrection methodology that explicitly models contemporaneous changes in the policy variable. The error-correction (ECM) representation corresponding to a general $\operatorname{ADL}(p, q)$ model is given by:

$$
\Delta y_{t}=\beta_{o} \Delta x_{t}+\delta\left(y_{t-1}-\alpha_{0}-\alpha_{1} x_{t-1}\right)+\sum_{i=1}^{q} B_{i} \Delta x_{t-i}+\sum_{i=1}^{p} \Gamma_{i} \Delta y_{t-i}+v_{t}
$$

where $\Delta$ denotes first difference operator; $\hat{\varepsilon}_{t-1}=\left(y_{t-1}-\alpha_{0}-\alpha_{1} x_{t-1}\right)$ represents the extent of disequilibrium at time $(t-1)$ and it is the residual of the long run relationship given by Equation (1); and $v_{t}$ is the error term. $\beta_{o}$ measures the contemporaneous or impact pass-through rate; $B_{i}$ and $\Gamma_{i}$ are dynamic adjustment coefficients; and $\delta$ captures the error correction adjustment speed when the rates are away from their equilibrium level. The sign of $\delta$ is expected to be negative due to the mean-reverting nature of interest rates. The same type of equation may be specified to describe the dynamics of adjustment in the policy rate $\left(\Delta x_{t}\right)$.

The mean adjustment lag (MAL) of a complete pass-through for a general $\operatorname{ADL}(p, q)$ model or its equivalent ECM parameterization, can be calculated using 
the formula given in Hendry (1995). For the special case of an ADL(1,1) model, this simplifies to:

$$
M A L=\left(\beta_{o}-1\right) / \delta
$$

The MAL is simply the weighted average of all lags and it is a measure of the speed with which retails rates respond to movements in policy rates.

Several studies have shown that the short-term adjustment may be asymmetric, in other words, the adjustment speed may differ when rates are above the equilibrium from that when rates are below (see Chong et al, 2005 and Scholnick, 1996). To test for the existence of asymmetric adjustments in the retail rates in New Zealand, we add a dummy variable, $\lambda$, to Equation (2). $\lambda$ is equal to one if the residual, $\hat{\varepsilon}_{t-1}$, is positive and 0 otherwise. The asymmetric short-run dynamic equation is as follows:

$$
\Delta y_{t}=\beta_{o} \Delta x_{t}+\delta_{2} \lambda \hat{\varepsilon}_{t-1}+\delta_{3}(1-\lambda) \hat{\varepsilon}_{t-1}+\sum_{i=1}^{q} B_{i} \Delta x_{t-i}+\sum_{i=1}^{p} \Gamma_{i} \Delta y_{t-i}+\eta_{t}
$$

where $\delta_{2}$ captures the error correction adjustment speed when the rates are above their equilibrium values and $\delta_{3}$ captures the error correction adjustment speed when the rates are below their equilibrium values. To test for the existence of asymmetric adjustment, we use the standard Wald test to determine if $\delta_{2}$ is significantly different from $\delta_{3}$.

As with the symmetric adjustment case, we can define the asymmetric mean adjustment lags (MAL) of a complete pass-through using the formula in Hendry (1995). For the special case of an $\operatorname{ADL}(1,1)$ model, this is given by:

$$
\begin{aligned}
& M A L^{+}=\left(\beta_{0}-1\right) / \delta_{2} \\
& M A L^{-}=\left(\beta_{0}-1\right) / \delta_{3}
\end{aligned}
$$

where $M A L^{+}$represents the mean adjustment lag when the retail interest rates are above their equilibrium value and $M A L^{-}$represents the mean adjustment lag when the retail interest rates are below their equilibrium value. 


\section{DATA AND ANALYSIS OF RESULTS}

Data

We use monthly series of interest rate data from two sources. The fixed mortgage rates of maturities of one to three years are obtained from a major commercial bank in New Zealand and the rest of the data, namely, the base lending rate, the floating mortgage rate and the six-month time deposit rate, the OCR and the overnight interbank rate, are all from the Reserve Bank of New Zealand. The sampling period is from August 1994 to December 2004, covering a time span of over 10 years. The sample size is 125 for most interest rate series.

Table 1 provides the descriptive statistics for the sample data. Panel A shows that descriptive statistics for the whole sample and Panel $B$ shows those for the subsample after the OCR was introduced which covers the period March 1999 to December 2004. The average fixed mortgage rates are positively related with maturity, indicating an upward sloping yield curve. Panel B also shows that the standard deviation of interest rates in New Zealand has decreased substantially with the introduction of OCR. Previously, the monthly volatility of interest rates was much higher, more than 1 percent for most series, with the overnight interbank rate having the highest monthly volatility at 1.72 percent. After the OCR was introduced, interest rates became much more stable than before, the monthly volatility of all the rates declined to the range of 0.6 to 0.75 percent. 
Panel A: The whole sample covering the period 1994:8 - 2004:12

* Starting from March 1999 when it was first implemented.

\begin{tabular}{|l|r|r|r|r|r|}
\hline Series & Mean & Median & Maximum & Minimum & Std.Dev. \\
\hline OCR & 5.43 & 5.38 & 6.50 & 4.50 & 0.63 \\
\hline Interbank & 5.44 & 5.53 & 6.50 & 4.07 & 0.64 \\
\hline Floating_rate & 7.49 & 7.58 & 8.77 & 6.50 & 0.68 \\
\hline Fixed_1YR & 6.91 & 6.85 & 9.25 & 5.90 & 0.65 \\
\hline Fixed_2YR & 7.27 & 7.15 & 8.70 & 6.25 & 0.59 \\
\hline Fixed_3YR & 7.55 & 7.50 & 8.80 & 6.30 & 0.61 \\
\hline Base_lending & 9.70 & 9.88 & 11.09 & 8.36 & 0.75 \\
\hline Time_deposit (6MTH) & 5.31 & 5.25 & 6.70 & 4.27 & 0.62 \\
\hline
\end{tabular}

Panel B: The after-OCR subsample covering the period 1999:3 - 2004:12 (No. of Obs. $=70$ )

\begin{tabular}{|l|r|r|r|r|r|r|}
\hline & \multicolumn{1}{|c|}{ Mean } & \multicolumn{1}{c|}{ Median } & \multicolumn{1}{c|}{ Maximum } & \multicolumn{1}{l|}{ Minimum } & Std Dev & Obs. \\
\hline OCR $^{*}$ & 5.54 & 5.50 & 6.50 & 4.50 & 0.65 & 70 \\
\hline Interbank & 6.54 & 6.15 & 10.00 & 3.30 & 1.72 & 125 \\
\hline Floating_rate & 8.67 & 8.44 & 11.50 & 6.50 & 1.56 & 125 \\
\hline Fixed_1YR & 8.04 & 7.50 & 11.50 & 5.90 & 1.49 & 125 \\
\hline Fixed_2YR & 8.27 & 7.95 & 11.50 & 6.25 & 1.30 & 125 \\
\hline Fixed_3YR & 8.41 & 8.25 & 11.50 & 6.30 & 1.17 & 125 \\
\hline Base_lending & 10.55 & 10.36 & 12.75 & 8.36 & 1.24 & 125 \\
\hline $\begin{array}{l}\text { Time_deposit } \\
\text { (6MTH) }\end{array}$ & 6.39 & 6.20 & 9.17 & 4.15 & 1.45 & 125 \\
\hline
\end{tabular}

Table 1: Descriptive Statistics

The pair-wise correlation coefficients between the various interest rates are reported in Table 2 . The OCR is shown to be highly correlated with the floating mortgage rate, the time deposit rate and base lending rate, but less correlated with the fixed rate mortgages. The OCR is also highly correlated with the overnight interbank rate. 


\begin{tabular}{|c|c|c|c|c|c|c|c|}
\hline & $\mathrm{OCR}^{*}$ & Interbank & $\begin{array}{l}\text { Floating_ } \\
\text { rate }\end{array}$ & $\begin{array}{l}\text { Fixed } \\
\text { 1YR }\end{array}$ & $\begin{array}{l}\text { Fixed_ } \\
2 Y R\end{array}$ & $\begin{array}{l}\text { Fixed_ } \\
\text { 3YR }\end{array}$ & $\begin{array}{l}\text { Base_- } \\
\text { lending }\end{array}$ \\
\hline Interbank & .984 & & & & & & \\
\hline $\begin{array}{l}\text { Floating_ } \\
\text { rate }\end{array}$ & 0.981 & 0.975 & & & & & \\
\hline $\begin{array}{l}\text { Fixed_ } \\
1 Y R\end{array}$ & 0.677 & 0.912 & 0.938 & & & & \\
\hline $\begin{array}{l}\text { Fixed_- } \\
\text { 2YR }\end{array}$ & 0.385 & 0.856 & 0.888 & 0.981 & & & \\
\hline $\begin{array}{l}\text { Fixed_- } \\
\text { 3YR }\end{array}$ & 0.230 & 0.814 & 0.844 & 0.959 & 0.990 & & \\
\hline $\begin{array}{l}\text { Base } \\
\text { lending }\end{array}$ & 0.931 & 0.952 & 0.973 & 0.863 & 0.796 & 0.744 & \\
\hline $\begin{array}{l}\text { Time } \\
\text { deposit }\end{array}$ & 0.931 & 0.972 & 0.984 & 0.960 & 0.918 & 0.880 & 0.941 \\
\hline
\end{tabular}

* Starting from March 1999 when it was first implemented.

Table 2: Correlation Coefficients

\section{Stationarity and Cointegration Tests}

Before carrying out cointegration tests, we need to determine whether the individual interest rate series are unit root processes and (thus) their firstdifference are stationary series. We test the null hypothesis of unit root against the alternative hypothesis of stationarity using the Phillips-Perron (PP) and the augmented Dickey-Fuller (ADF) procedures. The results of the stationarity tests on the various interest rate series are summarized in Table 3. For the level of the series, the results show that we cannot reject the hypothesis that all the series are unit root non-stationary at the $1 \%$ level of significance, and that all the first differenced series are stationary at the $1 \%$ level of significance, except for OCR whose first differenced series is stationary at the $5 \%$ level for the ADF test.

The results of the cointegration tests are reported in Table 4. The Johansen's Trace test is used. The results of the Johansen tests show that that all retail series are cointegrated with the interbank rate. ${ }^{i v}$ 
Phillips-Perron test

\begin{tabular}{|l|c|c|c|l|l|c|c|}
\hline \multicolumn{4}{|c|}{ Level } & \multicolumn{4}{c|}{ First difference } \\
\hline \multicolumn{1}{|c|}{ Series } & Prob. & Bandwidth & Obs & \multicolumn{1}{c|}{ Series } & Prob. & Bandwidth & Obs \\
\hline OCR & $33.5 \%$ & 5 & 69 & D(OCR) & $0.0 \%$ & 4 & 68 \\
\hline Interbank & $29.5 \%$ & 6 & 124 & D(Interbank) & $0.0 \%$ & 2 & 123 \\
\hline Floating_Rate & $36.3 \%$ & 6 & 124 & D(Floating_Rate) & $0.0 \%$ & 2 & 123 \\
\hline Fixed_1YR & $32.3 \%$ & 3 & 124 & D(Fixed_1YR) & $0.0 \%$ & 1 & 123 \\
\hline Fixed_2YR & $32.1 \%$ & 2 & 124 & D(Fixed_2YR) & $0.0 \%$ & 3 & 123 \\
\hline Fixed_3YR & $31.6 \%$ & 1 & 124 & D(Fixed_3YR) & $0.0 \%$ & 3 & 123 \\
\hline Base_lending & $26.4 \%$ & 6 & 124 & D(Base_lending) & $0.0 \%$ & 2 & 123 \\
\hline Time_deposit & $37.1 \%$ & 7 & 124 & D(Time_deposit) & $0.0 \%$ & 3 & 123 \\
\hline
\end{tabular}

ADF test

\begin{tabular}{|c|c|c|c|c|c|c|c|c|c|}
\hline \multicolumn{5}{|c|}{ Level } & \multicolumn{5}{|c|}{ 1st difference } \\
\hline Series & Prob. & Lag & $\begin{array}{l}\text { Max } \\
\text { Lag }\end{array}$ & Obs & Series & Prob. & Lag & $\begin{array}{l}\text { Max } \\
\text { Lag }\end{array}$ & Obs \\
\hline OCR & $6.1 \%$ & 2 & 10 & 67 & $\mathrm{D}(\mathrm{OCR})$ & $3.2 \%$ & 1 & 10 & 67 \\
\hline Interbank & $28.2 \%$ & 1 & 12 & 123 & $\mathrm{D}$ (Interbank) & $0.0 \%$ & 0 & 12 & 123 \\
\hline Floating_Rate & $14.8 \%$ & 2 & 12 & 122 & D(Floating_Rate) & $0.0 \%$ & 1 & 12 & 122 \\
\hline Fixed_1YR & $48.5 \%$ & 0 & 12 & 124 & D(Fixed_1YR) & $0.0 \%$ & 0 & 12 & 123 \\
\hline Fixed_2YR & $45.7 \%$ & 0 & 12 & 124 & D(Fixed_2YR) & $0.0 \%$ & 0 & 12 & 123 \\
\hline Fixed_3YR & $38.6 \%$ & 0 & 12 & 124 & D(Fixed_3YR) & $0.0 \%$ & 0 & 12 & 123 \\
\hline Base_lending & $20.3 \%$ & 1 & 12 & 123 & $\mathrm{D}$ (Base_lending) & $0.0 \%$ & 0 & 12 & 123 \\
\hline Time_deposit & $21.7 \%$ & 1 & 12 & 123 & D(Time_deposit) & $0.0 \%$ & 0 & 12 & 123 \\
\hline
\end{tabular}

Table 3: Unit Root Tests 


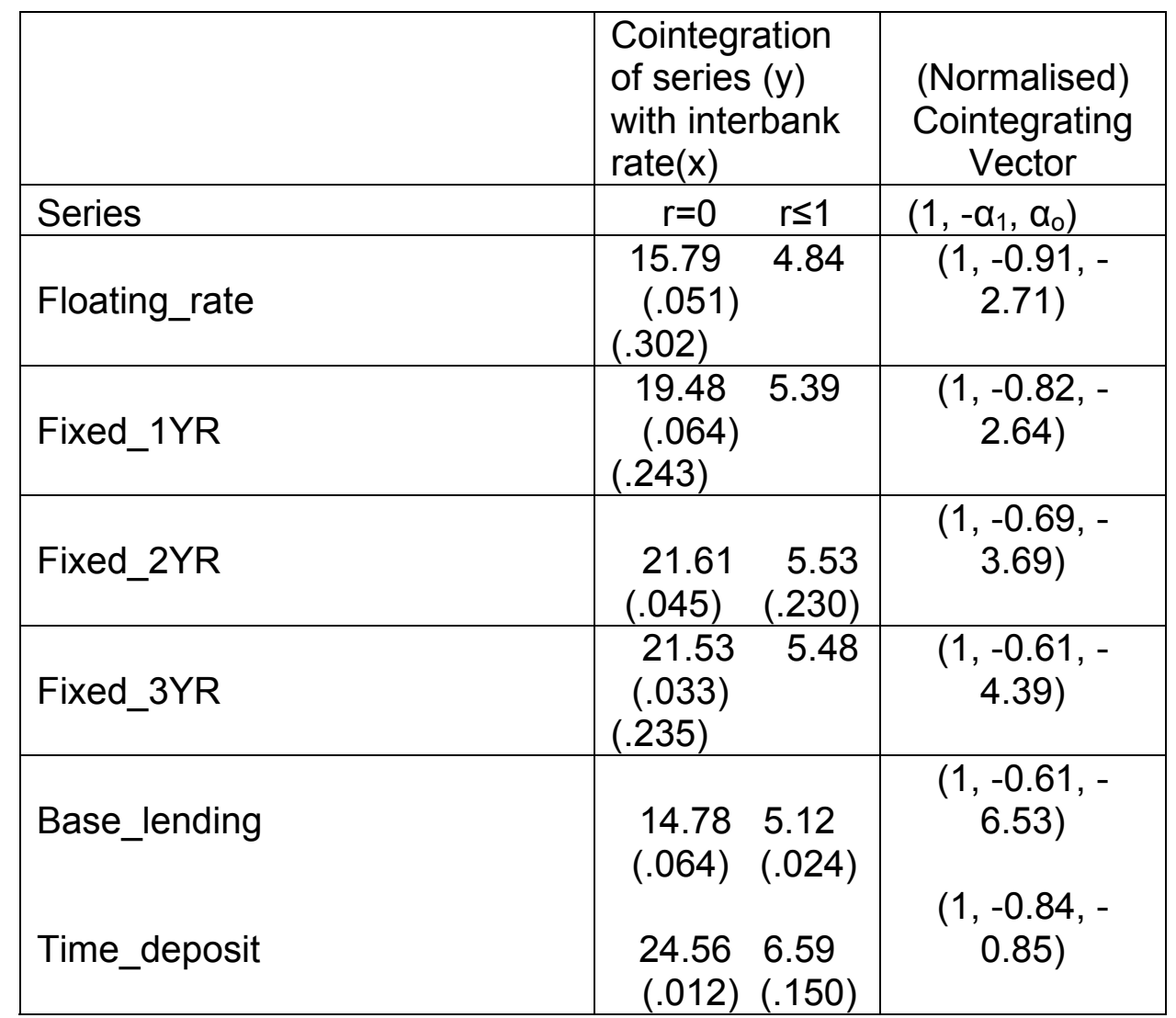

Numbers in brackets are MacKinnon-Haug-Michelis (1999) p-values.

Table 4: Johansen cointegration rank test (trace) results $\left(y_{t}=\alpha_{0}+\alpha_{1} x_{t}+\varepsilon_{t}\right)$

\section{Long-Term Pass-Through and Structural Change}

Having established that the overnight interbank interest rate is cointegrated with the various retail interest rates, we then estimate the long-term pass-through for the whole sample. The results of both Phillips-Loretan estimator and the OLS estimator are reported in Table 5. Our results show that the Phillips-Loretan estimates can differ quite substantially in some cases from the OLS estimates. Hence, the OLS results, especially t-values, should be interpreted with caution. On the other hand, from Tables 4 and 5 we can see that the Phillips-Loretan estimates are quite similar to those obtained by using the bivariate (VAR) Johansen model specification. ${ }^{v}$ 
Over the entire sampling period, the $x^{2}$ test statistic and $p$-values in the last two columns of Table 5 results show that the long-term pass-through is incomplete for all the series except the floating and fixed one-year mortgage rate at the 5 percent level. The slope coefficients are in the range of $58.8 \%$ to $93.4 \%$ (pass-through). In general, the degree of long-term pass-through is higher for short-term retail interest rates than that for longer-term rates. This is consistent with the expectation hypothesis of the term structure of interest rates. As the OCR is an overnight rate, it is more highly correlated with short-term rates than with long-term rates. Long-term rates are influenced not only by current shortterm rates but also future short-term rates.

\begin{tabular}{|l|r|c|r|r|r|r|r|l|}
\hline $\begin{array}{l}\text { Dependent } \\
\text { Variable (y) }\end{array}$ & Constant & $\begin{array}{l}\text { Constant } \\
(\mathrm{OLS})\end{array}$ & Slope & $\begin{array}{l}\text { Slope } \\
(\mathrm{OLS})\end{array}$ & $\mathrm{R}^{2}$ & $\mathrm{DW}$ & $\mathrm{X}^{2}\left(\alpha_{1}=1\right)$ & Prob. \\
\hline Floating_rate & $\begin{array}{r}2.498^{*} \\
(6.033)\end{array}$ & $\begin{array}{c}2.094^{*} \\
(11.258)\end{array}$ & $\begin{array}{r}0.934^{*} \\
(15.056)\end{array}$ & $\begin{array}{c}1.004^{*} \\
(29.529)\end{array}$ & 0.978 & 1.826 & 1.127 & 0.289 \\
\hline Fixed_1YR & $\begin{array}{r}2.780^{*} \\
(3.720)\end{array}$ & $\begin{array}{c}3.648^{*} \\
(6.775)\end{array}$ & $\begin{array}{c}0.793^{*} \\
(7.051)\end{array}$ & $\begin{array}{c}0.621^{*} \\
(6.402)\end{array}$ & 0.954 & 1.964 & 3.374 & 0.066 \\
\hline Fixed_2YR & $\begin{array}{r}3.742^{*} \\
(4.953)\end{array}$ & $\begin{array}{c}5.772^{*} \\
(9.717)\end{array}$ & $\begin{array}{c}0.686^{*} \\
(6.015)\end{array}$ & $\begin{array}{c}0.297^{*} \\
(2.776)\end{array}$ & 0.943 & 1.976 & $7.713^{*}$ & 0.006 \\
\hline Fixed_3YR & $\begin{array}{r}4.511^{*} \\
(5.236)\end{array}$ & $\begin{array}{c}6.857^{*} \\
(11.390)\end{array}$ & $\begin{array}{c}0.588^{*} \\
(4.532)\end{array}$ & $\begin{array}{c}0.147 \\
(1.349)\end{array}$ & 0.922 & 2.026 & $10.043^{*}$ & 0.001 \\
\hline Base_lending & $\begin{array}{r}3.825^{*} \\
(2.440)\end{array}$ & $\begin{array}{c}4.098^{*} \\
(15.701)\end{array}$ & $\begin{array}{c}0.761^{*} \\
(9.598)\end{array}$ & $\begin{array}{c}1.035^{*} \\
(22.021)\end{array}$ & 0.989 & 1.929 & $9.105^{*}$ & 0.002 \\
\hline Time_deposit & $\begin{array}{r}0.957^{*} \\
(2.688)\end{array}$ & $\begin{array}{c}0.445 \\
(1.503)\end{array}$ & $\begin{array}{c}0.825^{*} \\
(15.350)\end{array}$ & $\begin{array}{c}0.907^{*} \\
(17.113)\end{array}$ & 0.991 & 1.981 & $10.669^{*}$ & 0.001 \\
\hline
\end{tabular}

Notes: RHS Variable $(\mathrm{x})$ is interbank rate. The degree of pass-through is measured by the slope, $\alpha_{1}$.

* indicates significance at the 5 percent level.

Numbers in brackets are t-ratios of estimated coefficients (the null hypothesis is: $\alpha_{1}=0$ ); all estimates and statistics are computed using the Phillips-Loretan method unless otherwise stated. $\mathrm{x}^{2}\left(\alpha_{1}=1\right)$ is the test statistic for the hypothesis that the slope coefficient is equal to one (complete pass-through). DW values for OLS regressions (not reported here) are quite low indicating the presence of serial correlation and possibly misspecified (omitted) dynamics.

Table 5: Long-run Pass through (Phillips-Loretan Estimates) $\left(y_{t}=\alpha_{0}+\alpha_{1} x_{t}+\varepsilon_{t}\right)$ 
Since the shift to OCR in March 1999 represented a major change in New Zealand monetary policy, we test next if there is a structural change associated with the introduction of the new policy instrument. The standard dummy-variable test is used to test the stability of the constant and slope coefficients of Equation 1. The dummy variable (D) takes on the value of zero between August 1994 and February 1999 (i.e., prior to the introduction of OCR) and the value of one between March 1999 and December 2004 (i.e., after its introduction). The test results on long-term pass-through are reported in Table 6.

\begin{tabular}{|c|c|c|c|c|c|c|c|c|}
\hline & \multicolumn{2}{|c|}{ Constant } & \multicolumn{2}{c|}{ Slope } & \multicolumn{2}{c|}{ Dummy (D) } & \multicolumn{2}{c|}{$\begin{array}{c}\text { Slope Dummy } \\
\left(D^{*} x\right)\end{array}$} \\
\hline & Coef. & t-value & Coef. & t-value & Coef. & t-value & Coef. & t-value \\
\hline Floating_rate & 5.021 & $8.478^{*}$ & 0.629 & $8.720^{*}$ & -2.690 & $-3.831^{*}$ & 0.322 & $2.944^{*}$ \\
\hline Fixed_1YR & 4.141 & $3.613^{*}$ & 0.646 & $4.632^{*}$ & -0.199 & 0.128 & -0.086 & -0.341 \\
\hline Fixed_2YR & 5.018 & $3.220^{*}$ & 0.537 & $2.818^{*}$ & 1.471 & 0.855 & -0.371 & -1.341 \\
\hline Fixed_3YR & 5.162 & $3.497^{*}$ & 0.526 & $2.911^{*}$ & 1.272 & 0.714 & -0.304 & -1.070 \\
\hline Base-lending & 6.126 & $6.655^{*}$ & 0.674 & $6.020^{*}$ & -1.586 & $-2.054^{*}$ & 0.278 & $2.410^{*}$ \\
\hline Time_deposit & 2.983 & $5.794^{*}$ & 0.593 & $9.492^{*}$ & -2.053 & $-3.002^{*}$ & 0.216 & $1.954^{* *}$ \\
\hline
\end{tabular}

Notes: $\mathrm{D}$ is a dummy variable. $\mathrm{D}=0$ for observations before March 1999 and 1 otherwise.

The column under the heading "Slope Dummy" measure the changes in the long-term pass through after the introduction of the OCR regime.

* indicates significance at the 5 percent level; ** indicates significance at 10 percent.

Table 6: Structural Change (Phillips-Loretan estimates) $\left(y_{t}=\alpha_{0}+\alpha_{1} x_{t}+\alpha_{2} D+\alpha_{3} D^{*} x_{t}+\varepsilon_{t}\right)$

The results show that prior to the introduction of OCR in 1999, the longterm degree of pass-through for all series was in the range of $52.6 \%$ to $67.4 \%$, none of which is complete. In comparison, after the introduction of OCR, the degree of pass-through for the floating mortgage rate, the base lending rate and the 6-month deposit rate increased, but that for the fixed 1-3 year mortgage rates did not change significantly (at least not statistically). In fact the degree of pass through is statistically complete for the floating and base rates at the 5 percent level and for the 6-month deposit rate at the 10 percent level (the p-values for 
testing the hypothesis that the sum of the slope coefficients is equal to 1 in Table 6 are $0.653,0.746$ and 0.087 for the floating, base lending and 6-month deposit rate equations, respectively).

The increase in the long-term pass-through from official to retail rates is probably due to less interest rate volatility and more transparency and competition in the marketplace. After the introduction of OCR, interest rates, as expected, became much less volatile, as shown in Table 1. With more stable interest rates, we would expect bank interest rate adjustment costs to decrease and hence a higher degree of pass-through. In addition, with the introduction of OCR, there has been more transparency in the way policy is set and communicated to the financial markets resulting in more competition in the banking industry. Kleimeier and Sander (2005) also show that greater transparency in the conduct of monetary policy can increase the degree of longterm pass-through.

While the increased transparency in monetary policy and the subsequent decrease in volatility can explain the increase in the degree of long-term passthrough for floating interest rates and fixed deposit rates, it had no impact on the fixed mortgage rates. One possible reason is the heavy reliance of New Zealand banks on foreign borrowing.

Due to the negative savings rate of the household sector in New Zealand, banks and other types of financial institutions in New Zealand actively source their funding globally, in Eurodollar markets and the US money market in particular. A mixture of instruments such as bank loans, Euro commercial paper, medium term notes (MTNs) and bonds are used. In theory, the substantial amount of overseas borrowing should not render monetary policy in New Zealand less effective if banks effectively hedge against the currency risk in the foreign currency debt. By swapping it into fixed or floating domestic currency (i.e., New Zealand dollars) through foreign exchange (FX) swaps and cross currency 
interest rate swaps, the effective borrowing cost overseas would be about the same as that of domestic interest rate with the same maturity, ignoring transaction costs associated with the hedge. In this case, banks are borrowing synthetically from overseas. Under interest rate parity, changes in domestic interest rates would be reflected in the funding cost. If FX risk hedging is not done, then borrowing from overseas would have significant impact on the effectiveness of monetary policy in the country due to the leakage. In practice, short-term FX risk can be hedged easily through FX swaps, currency swaps, hedging against longer-term currency risk is more costly and less effective, reducing the effectiveness of domestic monetary policy. Further, if hedging is done using options, currency volatility as well as domestic interest rate can affect the hedging cost and hence the true funding cost, influencing the effectiveness of monetary policy on retail rates. Our results suggest that the longer term FX risk may not be hedged effectively in New Zealand.

\section{Short-Term Pass-Through and Adjustment Speed}

We use bivariate specifications of structural-error-correction (SEC) models to estimate the short-run dynamics of adjustment of retail interest rates and benchmark wholesale rates. The results of the retail interest rate adjustment are reported in Table 7 . We only report the estimates for the impact and error correction coefficients. Coefficient estimates for the other variables in the retail interest rate equations and the results of the interbank rate equations are not reported but are available upon request. All the parameters have the expected sign and are statistically significant. The impact pass-through coefficients, $\beta_{o}$, are positive and statistically significant. For fixed rate mortgages, the contemporaneous pass-through, ranges from $35.3 \%$ for the base lending rate to $86.2 \%$ for the 1 -year fixed rate. All the estimates of error correction speed or adjustment speed, $\delta$, are negative and statistically significant, indicating that the retail rates mean-revert to their long-run equilibrium values. The mean adjustment lags show a similar picture. It only takes less than a month for 1-year 
fixed rates to complete on average their adjustment but takes close to 4 months for the three-year fixed rate mortgages to go through the same process.

\begin{tabular}{|l|c|c|c|c|c|}
\hline Series & $\beta_{0}$ & $\mathrm{t}$-value & $\delta$ & $\mathrm{t}$-value & $\mathrm{MAL}$ \\
\hline Floating_rate & 0.415 & $1.87^{* *}$ & -0.321 & $-3.74^{*}$ & 0.94 \\
\hline Fixed_1YR & 0.862 & $4.20^{*}$ & -0.216 & $-3.14^{*}$ & 0.64 \\
\hline Fixed_2YR & 0.480 & $2.09^{*}$ & -0.154 & $-2.76^{*}$ & 1.75 \\
\hline Fixed_3YR & 0.486 & $2.49^{*}$ & -0.138 & $-2.53^{*}$ & 3.79 \\
\hline Base_lending & 0.353 & $6.46^{*}$ & -0.153 & -3.11 & 3.24 \\
\hline Time_deposit & & $8.50^{*}$ & -0.237 & $-3.54{ }^{*}$ & \\
& 0.829 & & & & 0.72 \\
\hline
\end{tabular}

MAL = mean adjustment lag (see Hendry 1995)

significant at $5 \%$ level; ${ }^{* *}$ significant at $10 \%$ level.

Table 7: Short-term pass-through and adjustment speed (SEC estimates) $\left(\Delta y_{t}=\sum_{i} \beta_{i} \Delta x_{t-i}+\sum_{i} \gamma_{i} \Delta y_{t-i}+\delta \hat{\varepsilon}_{t-1}+\eta_{t}\right)$

The short-term retail rates, e.g, the one-year fixed rate and the six-month time deposit rate show both greater degree of short-term pass-through and speedier adjustment. Banks have been known to compete intensely in these segments and more so under the OCR regime. Residential mortgages are very important for New Zealand banks. Over the past few years, they account for over 50 percent of all banks' loan portfolio. For some banks, it accounts for over 70 percent of their total loans and advances. In order to gain market share of residential mortgage, banks have been competing intensely with each other, especially in the short-term fixed rate mortgage market. ${ }^{v i}$ Competition for deposits is also very keen. As discussed earlier, the rate of savings in New Zealand is among the lowest in the industrialized countries and banks have to borrow a large amount of wholesale funds from overseas to finance their loan growth. Domestic deposits are preferable as they are more stable and less sensitive to changes in interest rates. 


\section{Asymmetric Adjustment Speed}

We estimate structural error-correction models that allow for different speed of adjustment towards equilibrium. The results on the asymmetric adjustment models are reported in Table 8. Comparing the asymmetric adjustment speed coefficients, $\delta_{2}$ and $\delta_{3}$, there is no evidence of asymmetric adjustment speed for any of the retail interest rates. We also estimated the impact of the introduction OCR on the asymmetric adjustment speed, there is no statistically significant difference either. There is some evidence to suggest that a differential speed of adjustment may exist for the base lending rate but the results are not conclusive. We also investigated the possibility that bank adjusted rates upwards at a different speed than adjusting them downwards during the post OCR period but there was no conclusive evidence to suggest that this is indeed the case. There was some weak evidence again that banks adjust rates faster upwards for base lending rates post OCR and also that they adjust rates faster downwards for the 1 -year fixed rate. The latter result may be indicative of the intense competition that is taking place among banks in recent years for market share in this particular market segment. 


\begin{tabular}{|l|c|c|c|c|c|c|}
\hline Series & $\beta_{0}$ & $\delta_{2}$ & $\delta_{3}$ & $\begin{array}{l}\mathrm{X}^{2} \\
\left(\delta_{1=} \delta_{2)}\right)\end{array}$ & MAL+ & MAL- \\
\hline Floating_rate & $\begin{array}{c}0.411^{* *} \\
(1.760)\end{array}$ & $\begin{array}{c}0.324^{*} \\
(3.118)\end{array}$ & $\begin{array}{c}-0.314^{*} \\
(2.381)\end{array}$ & 0.004 & 0.94 & 0.97 \\
\hline Fixed 1YR & $\begin{array}{c}0.802^{*} \\
(4.112)\end{array}$ & $\begin{array}{c}-0.220^{*} \\
(2.517)\end{array}$ & $\begin{array}{c}-0.296^{* *} \\
(1.928)\end{array}$ & 0.182 & 0.90 & 0.67 \\
\hline Fixed 2YR & $0.479^{*}$ & $-0.162^{*}$ & $-0.144^{* *}$ & 0.026 & 1.70 & 1.81 \\
& $(2.076)$ & $(2.156)$ & $(1.684)$ & & & \\
\hline Fixed 3YR & $0.483^{*}$ & $-0.145^{*}$ & -0.126 & 0.027 & 3.55 & 4.09 \\
& $(2.461)$ & $(2.041)$ & $(1.402)$ & & & \\
\hline Base_lending & $0.391^{*}$ & $-0.108 ;$ & $-0.214^{*}$ & 0.823 & 7.84 & 3.95 \\
& $(9.922)$ & $(1.426)$ & $(2.774)$ & & & \\
\hline \multirow{2}{*}{ Time_deposit } & $0.825^{*}$ & $\begin{array}{c}-.0 .248^{*} \\
(8.331)\end{array}$ & $\begin{array}{c}-.0 .219^{*} \\
(2.923)\end{array}$ & 0.049 & 0.70 & 0.80 \\
\hline
\end{tabular}

Notes: T-value in brackets. *significant at $5 \%$ level; ** significant at $10 \%$ level.

$D$ is a dummy variable. $D=0$ for observations before March 1999 and 1 otherwise.

Under the asymmetric $\mathrm{ECM}, \mathrm{MAL}^{+}$represents the mean adjustment lag when the retail rates are above their equilibrium value and $\mathrm{MAL}^{-}$represents the mean adjustment lag when the retail rates are below their equilibrium value. $\beta_{o}$ measures the degree of pass-through in the short-term.

Table 8: Short-term pass-through and asymmetric adjustment speed (SEC estimates) $\left(A: \Delta y_{t}=\sum_{i} \beta_{i} \Delta x_{t-i}+\sum_{i} \gamma_{i} \Delta y_{t-i}+\delta_{2} \lambda \hat{\varepsilon}_{t-1}+\delta_{3}(1-\lambda) \hat{\varepsilon}_{t-1}+\eta_{t}\right)$

\section{CONCLUSION}

In this paper we have examined the following issues: Firstly, we considered the long-term pass through of various retail interest rates including mortgage rates of different maturities. Secondly, we examined the short-term pass-through and the adjustment speed of those retail interest rates using an error correction and test whether the adjustment is symmetric or asymmetric. Finally, we investigated whether a change in monetary policy operating procedures as a result of the adoption of the Official Cash Rate (OCR) instrument in 1999 has had a different effect on the pass-through and adjustment speed of interest rates in New Zealand.

Our findings show that the long-term pass-through of retail rates varies across financial products. Short-term rates show a higher degree of pass-through 
and faster adjustment speed than long-term rates, but there is no evidence of significant asymmetric adjustment. We also find that the introduction of OCR is associated with an increase in the pass-through for floating and deposit rates but not for fixed mortgage rates. The latter result suggests that in a small open economy with a substantial amount of overseas borrowing the effectiveness of monetary policy may be weakened.

Overall, our results show that monetary policy rate has more influence on short-term interest rates. We also find evidence suggesting that increased transparency in the conduct of monetary policy has reduced the volatility of official policy rates and led to more competition in the banking industry. As monetary policy transparency increases and interest rate volatility decreases, future short-term rate changes become less uncertain, thereby enhancing the degree of pass-through of official rates to retail rates in tandem with the efficacy of monetary policy. 


\section{NOTES}

${ }^{1}$ The New Zealand financial system is dominated by banks. Bank assets account for $76 \%$ of the total assets of the financial system. Foreign own banks dominate the banking system. $98 \%$ of bank assets are owned by foreign banks, mostly Australian banks (RBNZ, 2005).

${ }^{2}$ OCR is typically reviewed at the release of the Reserve Bank's quarterly Monetary Policy Statements and about halfway between each Monetary Policy Statement. Unscheduled adjustments to the OCR are made only in exceptional circumstances. For example, OCR was adjusted shortly after the 11 September terrorist attacks on the United States in 2001.

${ }^{3}$ This is in contrast to the volatile experience with the $\mathrm{MCl}$ where markets, particularly those offshore, had at times difficulties reading the signals of policy.

${ }^{4}$ We assessed whether the overnight interbank can be used as a proxy of monetary policy stance. We adopt a two step procedure. First, we test the relationship between the two series over the period between March 1999 and December 2004. We find that the two series cointegrate using a Johansen test and that the slope coefficient has an estimated value of .99 which is insignificantly different from one (Johansen cointegrating restriction $x^{2}$ test $p$-value=.19). Secondly, we estimate the long-term relationship between OCR and the various retail interest rates over the same period. We also estimate the long-term relationship between the overnight interbank interest rate and the various retail rates over the same period. The results are very similar using either the OCR or the overnight rate, indicating that the overnight interbank rate can be used as a proxy for the monetary policy stance, which is a common practice in the literature (Chong et al, 2005). To test for robustness, we also used the 90 T-bill rate as an alternative measure of the market benchmark rate. The results are similar to those of using the interbank rate.

${ }^{5}$ It is possible that the finite bias of the OLS estimator may be less or negligible compared to the other two estimators for floating and possibly base-lending rates to the extent that there are no dynamics in the DGP for those interest rates (as banks typically adjust them in full after a policy change) and switching or menu costs are unimportant.

6 As at March 2005 , about $25 \%$ of mortgages are priced on a floating rate basis and $75 \%$ on a fixed rate basis. Among the fixed rate mortgages, $30 \%$ out of the $75 \%$ is fixed for up to one-year, $35 \%$ fixed for one to two year, and only $10 \%$ are for the remaining fixed terms (i.e., three and five-year fixed rates). 


\section{REFERENCES}

Altunbas, Y. O. Fazylov and P. Molyneux. (2002) "Evidence on the bank lending channel in Europe". Journal of Banking and Finance 26, 2093-2110.

Bernanke, B., Gertler, M., (1995) "Inside the black box: The credit channel of monetary policy transmission”. Journal of Economics Perspective 9, 27-48.

Bondt, G. D., (2002) "Retail bank interest rate pass-through: New evidence from the Euro area level". Working paper No.136, European Central Bank Working Paper Series.

Chong, B. S., Liu, M. H., Shrestha, K. (2005) "Monetary transmission via the administered interest rate channel". Journal of Banking and Finance, Forthcoming.

Cottarelli C., Kourelis A., (1994) "Financial structure, bank lending rates, and the transmission mechanism of monetary policy". IMF Staff Papers 41, 587 623

Dutta, S., Bergen, M., Levy, D., Venable, R., (1999) "Menu costs, posted prices, and multiproduct retailers", Journal of Money, Credit, and Banking 31, 683703.

Guthrie, G., Wright, J., (2000) "Open mouth operations". Journal of Monetary Economics 46 (2), 489-516.

Hannan, T., Berger, A., (1991) "The rigidity of prices: Evidence from banking industry". American Economic Review 81: 938-945.

Heffernan, S.A., (1997) Modelling British interest rate adjustment: An error correction approach. Economica 64, 211-31.

Hendry, D.F., (1995) "Dynamic Econometrics". Oxford University Press, Oxford.

Hofmann, B., Mizen P., (2004) "Interest rate pass-through and monetary transmission: Evidence from individual financial institutions' retail rates". Economica 71, 99-123.

Huang, A., Margaritis, D., Mayes, D., (2001) "Monetary policy rules in practice: Evidence from New Zealand”. Multinational Finance Journal, 5 (3), 175-200.

Kashyap A. K., Stein. J., (2000) "What do a million observations on banks say about the transmission of monetary policy". American Economic Review 86, 310-14.

Kleimeier, S., Sander H., (2005) "Expected versus unexpected monetary policy impulses and interest rate pass through in euro-zone's retail banking markets". Journal of Banking and Finance, accepted and forthcoming.

MacKinnon, J. G., Haug, A.A. and Michelis L., (1999) "Numerical distribution functions of likelihood ratio tests for cointegration". Journal of Applied Econometrics, 14, 563-577.

Mojon, B., (2000) "Financial structure and the interest rate channel of the ECB monetary policy", Working paper No. 40, European Central Bank Working Paper Series.

Neuman D., Sharpe, S., (992) "Market structure and the nature of price rigidity: Evidence from the market for consumer deposits". Quarterly Journal of Economics 107, $657-680$.

Paisley, J., (1994) "A model of building society interest rate setting". Bank of England Working Paper 22. 
Phillips, P. C. B. and Loretan, M., (1991) "Estimating long-run equilibria", The Review of Economic Studies 58(3), 407-436.

Reserve Bank of New Zealand, (2005) "Financial Stability Report". May, Wellington, New Zealand.

Rousseas, S., (1985) "A markup theory of bank loan rates", Journal of Post Keynesian Economics 8, 135-144.

Sarno, L., Thornton, D.L., (2003) "The dynamic relationship between the federal funds rate and the Treasury bill rate: An empirical investigation". Journal of Banking and Finance 27, 1079-1110.

Scholnick, B., (1996) "Asymmetric adjustment of commercial bank interest rates: evidence from Malaysia and Singapore". Journal of International Money and Finance 15, 485-496.

Spencer, G., (1992) "Monetary policy: The New Zealand experience". In Monetary Policy and the New Zealand Financial System, 3rd ed., Reserve Bank of New Zealand, Wellington, New Zealand.

Stiglitz, J., Weiss, A., (1981) "Credit rationing in markets with imperfect information". American Economic Review 71, 393-410. 


\section{FACULTy of Business ReseARCh PAPER SERIES}

01-2003 SIMON MOWATT and HOWARD COX

02-2003

BILL DOOLIN, BOB MCQUEEN and MARK WATTON

03-2003 ROGER BAXTER and SHEELAGH MATEAR

04-2003 HOWARD COX and SIMON MOWATT

05-2003 CHRISTOPHER BOgGS, BRETT COLLINS and MARTIE-LOUISE VERREYNNE

06-2003 MARK GLYNN, JUDY MOTION and RODERICK BRODIE

07-2003 DERYL NORTHCOTT and LI-CHENG CHANG

08-2003 ROY SMOLLAN and JONATHAN MATHENY

09-2003 ROBIN H. LUO and L. CHRISTOPHER PLANTIER
Innovation Networks and the Development of Consumer-Driven ICT-Based Management Systems

Internet Strategies for Established Retailers: Five Case Studies from New Zealand

Measuring Intangible Value in Business to Business Buyer-Seller Relationships: An Intellectual Capital Perspective

Technology, Organisation and Innovation: The Historical Development of the UK Magazine Industry

Examining the Effects of Referent Power on Intrinsic Motivation in Organisations: A SelfConcept Based Approach

Retailers' Perceived Value of Manufacturers' Brands

The Use of Performance Measurement as an Accountability Mechanism: A Case Study in the UK National Health Service

Emotions Experienced Through Organisational Events: An Exploratory Framework of Perceived Justice and Outcomes

The Persistence of NZ Dollar Misalignments Relative to Purchasing Power Parity 
10-2004 SIMON MOWATT

11-2004 HELEN ANDERSON and JONATHAN MATHENY

12-2004 AARON GILBERT, AlireZA TOURANI-RAD and TOMASZ WISNIEWSKI

13-2004 AARON GILBERT, ALIREZA TOURANI-RAD and TOMASZ WISNIEWSKI

14-2004 AARON GILBERT, AliREZA TOURANI-RAD and TOMASZ WISNIEWSKI

15-2004 JULIE DOUGLAS

16-2005 Glen Oliver and Peter MCGHEE

17-2005 PAUL WELLS

18-2005 PAUL Wells and Peter FIEGER

19-2005 RACHEL MORRISON

20-2005 MARTIE-LOUISE VERREYNNE

21-2005 BART FRIJNS, AARON GILBERT and ALIREZA TOURANI-RAD
New Perspectives on the Supply-Chain and Consumer-Driven Innovation

Paying Attention To The Construct Of Salience In Identity-related Literature and Beyond

The Impact of Regulatory Change on Insider Trading Profitability: Some Early Evidence from New Zealand

Do Insiders Crowd Out Analysts?

Insiders and the Law: The Impact of Regulatory Change on Insider Trading

Wages and Conditions of Clinical Coders in New Zealand. A report of surveys conducted in 1998 and 2004

In Search of Professional Identity: $A$ Descriptive Study of New Zealand "Professional" Bodies' Codes of Ethics

The Supply of Accounting Graduates in New Zealand

Accounting: Perceptions of Influential High School Teachers in the USA and NZ

Testing for the Invariance of a Causal Model of Friendships at Work: An Investigation of Job Type and Needs

Strategy-Making Process and Firm Performance in Small Firms

Insider Trading, Regulation and the Components of the Bid-Ask Spread 
22-2005

BELINDA LUKE and MARTIE-LOUISE

VERREYNNE

23-2005 MING-HUA LIU, DIMITRI MARGARITIS and ALIREZA TOURANI-RAD

24-2005 HARDJO KOERNIADI and ALIREZA TOURANI-RAD
Exploring Entrepreneurship in the Public Sector: Examining the Application of Strategic Entrepreneurship to SOES

Monetary Policy Transparency and Pass-

Through of Retail Interest Rates

Accruals and Cash Flows Anomalies: Evidence from the New Zealand Stock Market 